\title{
ESTUDOS
}

\section{Representações Sociais: Pressupostos e Implicações}

Margot Campos Madeira

Universidade Federal da Paraíba (UFPB)

A representação social é abordada neste artigo como a particularização, num objeto, do processo mais amplo de apreensão e de apropriação do real pelo homem, enquanto sujeito-agente situado num tempo e num espaço. A categoria de totalidade, o princípio de contradição e a lei do movimento são os instrumentos básicos para a construção da proposta teórica. São levantadas algumas implicações relativas à aplicação desta abordagem a questões concretas da educação.

\section{Uma nova abordagem ou mais um modismo?}

Muito se fala, hoje, em representação. Este termo, contudo, tanto é empregado no sentido de reprodução mental do objeto, como no de atividade isolada e intrapsíquica, ou significando construção coletiva, para citar apenas alguns empregos. Subjacentes ao uso de uma mesma terminologia estão posições teóricas diversas e, até, categorias de análise antagônicas.

Neste texto, referimo-nos à representação como "representação social".

Antes de mais nada, importa precisar que nos inserimos no meio teórico aberto por Moscovici (1961) ao retomar, reformulando, a questão das representações coletivas trabalhadas por Durkheim (1968). Para Moscovici, as representações são fenômenos complexos que extrapolam categorias puramente lógicas e invariantes. Organizam-se como um saber acerca do real que se estrutura nas relações do homem com este mesmo real, "...reconhecendo que as representações são ao mesmo tempo geradas e adquiridas, retira-se-lhes este caráter preestabelecido, estático, que elas tinham numa visão clássica. Não são os substratos, mas as interações que contam" (Moscovici, 1989, p.82).

Queríamos, ainda, acrescentar que, embora uma representação se construa em torno de objetos precisos, reais ou imaginários, sejam eles pessoas, idéias, teorias, acontecimentos (Jodelet, 1989), ela não pode ser apreendida no isolamento ou na dicotomia entre o que se pretende captar e analisar e o viver concreto dos sujeitos.

Se a representação social é tomada como particularização em tomo do objeto, por que este quadro tão abrangente, tão amplo? A resposta a esta e a outras questões nela implicadas constitui-se o objeto deste trabalho.

O enfoque psicossocial aqui assumido pretende ultrapassar a dicotomia 
de análises que tomam o social ou o psicológico como pontos isolados, a partir dos quais dariam conta do fenômeno em estudo.

O processo de Veiculação de idéias e de hábitos, bem como o de estruturação do pensamento e da linguagem, por exemplo, não existem no vazio. $\mathrm{Pa}$ ra sua apreensão, necessário se faz que eles sejam tomados de forma integrada e articulada ao concreto do homem que lhes é agente e sujeito. Neste conjunto, "as representações sociais, enquanto sistemas de interpretação que regem nossa relação com o mundo e com os outros e organizam as comunicações e as condutas sociais" (Jodelet, 1989, p.36), não são uma reprodução do real no plano subjetivo, mas sua reorganização significativa, pela qual cada objeto apropriado tem seu espaço e seu contorno. Isto porque a representação social é, por definição, a particularização, num objeto, do processo mais amplo de apreensão e de apropriação do real pelo homem, enquanto sujeito-agente situado. Sob este enfoque, não é possivel estudá-la sem que se apreenda, pode-se assim dizer, o "lugar", no concreto, do homem que a estrutura e que, através dela, se comunica e age.

Estão em jogo as relações mutuamente constitutivas entre o individual e o social enfocadas a partir do que se convencionou chamar de campo de representações sociais. Este atua como um "filtro interpretativo" (Abric, 1989, p.191), que determina comunicações e condutas.

Destas colocações, infere-se que a estruturação de uma representação se enraíza no processo de atribuição de sentido ao objeto. Este processo, mais uma vez frisamos, não se opera no indefinido, no vago. Vincula-se às articulações do objeto, à história pessoal do sujeito, enquanto marcada por determinantes de diferentes níveis e ordens. Vincula-se, outrossim, à significação que este sujeito atribui ter o objeto para os outros que ele tem como referências e às formas e às implicações de todas essas articulações. "Isto significa dar prioridade aos vínculos intersubjetivos e sociais mais do que aos com o objeto. Em outros termos, o vínculo com o objeto é parte intrínseca do lugar social e deve, então, ser interpretado neste quadro. Nossas representações comuns parecem, assim, determinar a natureza de nossos comportamentos e de nossas informações" (Moscovici, 1986, p.71).

A atribuição não é aqui tomada, portanto, como algo definitivo ou indiferenciado, mas como intrinsecamente processual; assim, o homem relaciona e integra informações e experiências; assim, estruturam-se e associam-se conceitos, imagens, valores, normas, símbolos e crenças, numa explicação do real e de suas partes. Neste sentido, o real torna-se concreto para o homem, que, desta forma, se insere e se (re)produz ao produzi-lo e ao ser por ele produzido.

Nestas colocações estão subjacentes duas ordens de idéias complementares: 1-) que o real só existe para o homem enquanto real-significado, concreto; 2-) que este real não é significado uniforme, abstrata, unitária ou isoladamente, mas a partir da experiência que atualiza, ratificando ou retificando o já apropriado, ou seja, o já vivido.

As premissas, até aqui colocadas, exigem que se busque aprofundar seus fundamentos de forma a permitir que o sentido de determinações e articula- 
ções nelas implicadas possa surgir com maior clareza. É o que procuraremos fazer nos dois itens que se seguem.

\section{Totalidade como categoria de análise: algumas implicações}

Ao falarmos em experiência ou em vivido, não estamos assumindo a postura que, num mesmo movimento, os individualiza, isolando o sujeito dos outros, dicotomizando-o em si mesmo, em nome de uma psyché tomada abstrata. Referimo-nos à experiência e ao vivido enquanto prática, no sentido de movimento que constrói e que expressa significações, a partir da forma peculiar de inserção deste homem na totalidade social. Isto não se dá na abstração ou no isolamento, mas na relação. As significações não são, portanto, nem iguais, nem dicotomizadas entre si. Articulam-se na especificidade das diferentes formas de inserção, integrando o subjetivo e o objetivo na concretitude do indivíduo social. "Trata-se de colocar o acento sobre a articulação entre o universo psíquico próprio aos sujeitos singulares e sua posição enquanto membros, quer dizer, partes que se fazem em partes interessadas e partes constituintes de um conjunto social' (Kaès, 1989, p.104).

A categoria de totalidade aplica-se, em primeira instância, ao processo histórico que se constrói em momentos sucessivos, nas relações dialéticas dos homens entre si e com a natureza Neste processo não existem, isoladamente, nem o fato nem o homem, mas momentos articulados de sínteses provisórias pois sempre superáveis.

A consideração do concreto como totalidade implica idéias de pluralidade (tomada como complementariedades e oposições) e de movimento. Supõe que se admita que sua especificidade, enquanto todo dinâmico num dado tempo e espaço, decorre da correlação de forças entre as partes que, por sua vez, têm sua própria especificidade, enquanto totalizações de outras partes e, assim, sucessivamente. Acarreta, também, que se tenha em vista os determinantes que, garantindo a especificidade das partes, as articulam.

Afirma-se, por esta argumentação, a diversidade, como decorrência de formas complementares e opostas de inserção na totalidade, e a igualdade, à medida que todas são partes e nenhuma, por si só, se constitui no que, numa idealização, se chamaria o todo.

Pretender a igualdade como uniformidade abstrata equivale a negar a especificidade das partes e a ratificar, como o único possivel, o que é próprio de uma delas: o específico daquela que na correlação de forças assume a dominância. Neste caso, um particular se toma o geral A partir daí, sua especificidade transmuta-se na única lei possível e os determinantes que o originam e Ihe dão substância se camuflam. Nega-se a totalidade porque se pretende um todo inteiro, monolítico, imutável. Não se aceita, tampouco, a possibilidade de transformações, enquanto o novo que se constrói historicamente nas relações entre as partes. Ao contrário, exigem-se mudanças, ou seja, as partes tornarse-iam "iguais" pela imposição e assimilação do que seria específico da domi- 
nante. A perspectiva de transformação não pode ser aceita, uma vez que supõe uma forma nova gerada nas relações possíveis como anterior. A dominação e a manipulação do homem pelo homem implicadas nesta postura nos parecem evidentes.

A categoria de totalidade permite a apreensão do concreto em construção, de sua dinâmica, de seu processo. Seria, no entanto, ilusório e uma negação, em termos, aplicá-la à análise do concreto, excluindo-se dele o homem. "O ponto de vista da totalidade não determina, entretanto, somente o objeto, determina também o sujeito do conhecimento" (Lukács, 1960, p.48).

Pensar o homem como totalidade implica a superação de dicotomias que o fragmentam, por considerarem isoladamente o que existe enquanto pólo de relação, em diversos níveis e dimensões. A fragmentação distorce a possibilidade de apreensão desta totalidade orgânica, dinâmica e articulada, que é o homem. Nesta totalidade não se pode captar a significação, a importância de um elemento, de uma dimensão ou de um nível, na emissão de suas relações, não só no próprio conjunto e com ele, mas, também, com a totalidade social com a qual o homem se articula de forma mutuamente constitutiva. A inserção do homem numa totalidade social, nesta perspectiva, não é, apenas, um fato externo. É um processo que o atinge, estruturalmente, enquanto o constitui, ao mesmo tempo em que, por este mesmo processo, o concreto também se consconstitui enquanto tal.

O apreender o mundo, dele se apropriar e nele intervir-se radica nesta dinâmica, caracterizando o pensar e o agir de grupos e segmentos determinados por esta mesma inserção. Identificam, portanto, partes de uma totalidade. Constróem e expressam este homem concreto, no mesmo movimento em que o concreto se constrói e encontra expressão. E na prática e pela prática que este processo se opera.

Nesta linha de análise, deixa de ter sentido a dicotomia entre afetivo, emocional, subjetivo, individual e o que lhes seria oposto, ou seja, o efetivo, o racional, o objetivo e o social. A racionalidade, tanto quanto a afetividade e a emotividade, se vincula e opera no concreto como síntese possível e dinâmica de um processo histórico que a extrapola. Todas estas dimensões articulam-se à especificidade da parte pela qual o sujeito se integra em determinada totalidade social.

Com isto não estamos, artificialmente, isolando as partes de uma totalidade social entre si. Antes, pretendemos enfatizar que os referentes que as estruturam não têm origem no vazio, mas nas relações com o concreto.

Estas colocações põem em questão um conjunto estabelecido de estereótipos, através dos quais se pretende afirmar uma pretensa racionalidade única, neutra, a partir da qual se garantiria a neutralidade à ciência e, mais ainda, a justeza de certas determinações, medidas e posturas.

Em sua organização e desenvolvimento, os referenciais que estruturam a racionalidade estão em profunda articulação com a especificidade da inserção do sujeito no concreto. Valores e símbolos que marcam esta inserção, marcam, também, a percepção dos fatos e as condições de sua decodificação. "Os valo- 
res das classes sociais agem sobre a estrutura categorial dos pensadores, e condicionam sua percepção dos fatos" (Lowy, 1985, p.144). Percepção significa, portanto, o movimento de um sujeito situado, na relação com o concreto em construção. As diferenças decorrem do processo histórico de estruturação do homem e do concreto, do momento e do espaço em que a racionalidade se toma ato, dir-se-ia, "atualiza-se".

Queremos, através desta linha de argumentação, enfatizar que a racionalidade não está imune à ideologia. Ao pensar, o sujeito o faz a partir dos referentes possíveis. Não está aqui, em jogo, a afirmação de uma dependência linear entre infra-estrutura e superestrutura, o que seria, a nosso ver, cair num mecanicismo rígido, pois isso se constituiria na própria negação do movimento, da contradição. Não se trata, tampouco, de optar por um idealismo abstrato que colocaria a racionalidade para além das condições estruturais e conjunturais de uma totalidade social. Ao contrário, quer-se levantar a questão da complexidade que envolve sua estruturação e comunicabilidade.

A distinção entre racionalidade cognitivo-instrumental e racionalidade comunicativa proposta por Habermas (1987 e 1990) faz ressaltar esta complexidade e indica pistas para um maior aprofundamento no estudo do fenômeno.

Para esse autor, "a racionalidade científica pertence a um complexo de racionalidade cognitivo-instrumental que pode, seguramente, pretender a validade para além do contexto de uma cultura particular" (Habermas, 1987, t.1, p.81). A pertinência de tal afirmação é evidente. Tendo em vista a especificidade do objeto inerente à racionalidade científica, no que concerne à validade e à comunicabilidade de seus resultados, a totalidade com a qual ela se articula pode assumir abrangência para além de limites geográficos e culturais.

Note-se, no entanto, que a racionalidade científica não existe independente das condições histórico-estruturais que a tornam possível, isto é, que lhe dão origem e intercomunicabilidade: tanto a possibilidade de decodificação de referentes, quanto sua determinação, bem como a de objetos, não existem senão em articulação com o concreto que lhes está na base. Isto porque é pelo sujeito, enquanto agente, que ela é efetivada, e este não se constitui como tal sem a outra dimensão da racionalidade, ou seja, sem o que Habermas denomina de racionalidade comunicativa. É através desta que ele interage e se integra, que ele se faz.

A racionalidade comunicativa, como o pensar pelo qual o sujeito se define ao definir o mundo e ao orientar suas ações, estrutura-se em relação às idéias que moldam este mundo e que chegam ao homem a partir das experiências de sua prática. Esta, como já expusemos anteriormente, não se constitui como ações fragmentadas ou fatos sem ligação entre si, e nem mesmo como o somatório de ações. Entendemos a prática como um processo através do qual o homem se constrói e se expressa, no dinamismo de um concreto, que assim se faz.

Neste sentido, a racionalidade comunicativa diz respeito ao que chamaríamos de simbólico. Este, estruturando-se na prática, integra em si outras dimensões desta totalidade que é o homem e está na base de seu agir e pensar 
quotidianos. Como a racionalidade científica articula-se com esta base, pois no homem não há cortes, as condições de apreensão, de decodificação e de construção de objetos pela racionalidade cientifica passam por este potencial simbólico. Ainda que, por seu objeto, a racionalidade científica suponha processos específicos, tanto de estruturação e de desenvolvimento quanto de comunicação, estes são construídos pelo homem a partir de suas condições simbólicas. Logo, ela é, também, e a seu modo, tributária da ideologia, uma vez que é, igualmente, uma prática, embora com objeto e linguagem específicos. Seus processos e procedimentos são construídos pelo homem a partir daquelas condições.

A possibilidade da passagem de elaborações da racionalidade científica em termos comunicativos é uma questão atual e está subjacente aos processos e instrumentos de vulgarização científica ou de transferência de tecnologia. Pela especificidade dos termos que levanta, a análise desta problemática extrapola os limites deste trabalho ${ }^{1}$. Cabe-nos, apenas, ressaltar a importância de uma posição crítica, frente à lógica e aos objetivos, implícitos ou declarados, que regem esta passagem. Da mesma forma que o homem que produz o conhecimento científico não existe independente de um tempo e de um espaço precisos e do jogo de interesses que determina as relações que os estruturam, também não existem, independentes destes, tanto aqueles que veiculariam sua produção, como os destinatários das mensagens assim veiculadas.

Não é, apenas, a possibilidade da transposição de códigos que está em jogo, como se, de um lado, existisse um aparato científico uniforme, amorfo e, de outro, uma massa também uniforme com um único núcleo de significações. A própria questão da intercomunicabilidade da racionalidade comunicativa precisa ser abordada à luz da pluralidade que caracteriza uma totalidade. Esta pluralidade se traduz, ao nível do pensamento e da linguagem, na diversidade de referentes e de significações que identificam e dão especificidade e condições de relação às partes. A construção do sentido e sua comunicação se processam nessas relações.

Nesse contexto, a ideologia, como conjunto de idéias que sustentam e servem aos interesses que polarizam determinada totalidade social, é apropriada de forma diversa e complementar, a partir do espaço do sujeito nessa mesma totalidade.

Cumpre, então, destacar dois aspectos:

$\left.1^{9}\right)$ È artificial prender-se ao corte entre o que seria a ideologia dominante e o que se the oporia, ou seja, a ideologia dos dominados. Não são objetos distintos que estão em jogo. $\mathrm{E}$ a apropriação de um mesmo objeto que se faz diversamente, a partir da especificidade das partes de uma mesma totalidade. Esta consideração é de suma importância para que não se distorça, camufle, ou perca de vista o objeto em questão. A distinção deve ser estabelecida, não

Ver, a este propósito, Astolfi e Giordan (1973), Belisle e Schiele (1984), Jacobi e Schiele (1988), Protée(v.16,n. A3, 1988), Moscovici e Hewstone (1984). 
na afirmação da ideologia, mas na sua potencial negação. Tocamos, aqui, no segundo aspecto que pretendemos destacar.

$2^{\circ}$ ) A ideologia, enquanto totalidade submetida â contradição e à lei do movimento, admite em si própria sua potencial negação. Ora, todo o seu dinamismo e os mecanismos de que se serve são polarizados na erradicação deste potencial que, se atualizado, significaria a negação de si própria, ou seja, a negação da negação. Esta negação se enraíza no confronto que o homem vive entre o que the vem da legitimação de uma ordem do mundo vigente, à qual ele adere, pois nela se reconhece, e o questionamento que o toma a partir da concretitude de sua experiência. É evidente que este potencial de negação se estrutura diferentemente, a partir da especificidade da inserção desse mesmo homem no concreto: quanto mais distante estiver uma parte de outra, cujos determinantes são os que dominam uma totalidade, mais agudo será esse confronto. Será mais angustiante e radical também, porque leva o individuo a questionar a estabilidade de um mundo que o faz e no qual ele se vê, quando ainda não encontra meios de agenciar outro.

Esta situação de dissonância leva o sujeito a abafar os conflitos por diferentes mecanismos ou, se existirem condições históricas concretas, a canalizar sua expressão, atualizando, desta forma, o que estava em potencial. O importante é frisar, tanto num caso como noutro, a atuação de mecanismos que buscam reduzir contradições e conflitos, mesmo incipientes.

Há, nesse processo, distinções e polarizações, como há, também, por parte da ideologia, formas diversas de recuperação e de desvio dessa negação em potencial.

O trabalho da ideologia é, justamente, subtrair o espaço de questionamento ou dele se apropriar pela afirmação de um concreto à sua maneira. Assim, ela muda e comporta evolução, impulsionada pela necessidade de se colocar em face da problemática que a sua negação, mesmo potencial, vai expondo.

Pretender que a racionalidade exista independente desse complexo é uma forma de mascará-lo. Pretender mudá-lo, sem a consideração do processo que vai se construindo neste jogo de negação-afirmação-negação, é impor um modelo sem história - ou partir de uma história assim decodificada por uns poucos "iluminados" -, o que equivale igualmente a sua negação. Pretender encontrar a história na consideração da angústia dessa potencial negação poderia ser um caminho. Um caminho que se faz com o homem concreto, com suas dores e esperanças, e não um caminho feito para que ele marche.

Falar em dores e esperanças pode até parecer deslocado, mas são homens em carne e osso que estão a caminhar. O afetivo e o emocional, também, não se enraizam num individual abstrato ou isolado, mas vão se contruindo no concreto da vida de cada sujeito, que é a de seu grupo, de sua classe, em relação com outras classes, num dado tempo e em determinado lugar.

O pensar, o compreender, o sentir, o relacionar-se e o agir do homem não são, portanto, nesta linha teórica de análise, aspectos isolados entre si nem 
desvinculados do concreto. Não são, também, estruturas acabadas, rígidas, ainda que seus componentes básicos se mantenham em estabilidade e evoluam na direção do seu possível. São dimensões de um mesmo processo: o construir-se homem no concreto. Expressam formas de inserção na totalidade social, no mesmo movimento em que nela são gerados e a ratificam.

Se o homem fosse estático, acabado ou compartimentado, e seu pensar e agir decorressem de uma lógica unificadora e uniforme, isto seria a negação do movimento e do espaço de liberdade que se constitui na dialética das relações deste homem consigo mesmo e com os outros, pelo seu potencial questionador. Tal postura acarretaria a negação do próprio homem enquanto indivíduo que se forma e reage no social, construindo-se.

Por outro lado, esse posicionamento implicaria, também, projetar numa idealização - lógica unificadora e uniforme - a raiz do que seria então definido como a essencialidade do homem. A partir disto, todos seriam iguais, não porque partes constitutivas de uma totalidade, mas porque cópias de determinado modelo.

No mínimo, uma questão se impõe: quem define o modelo e a partir de que ele seria definido?

Nem o concreto nem o homem podem ser considerados, quer isoladamente quer em conjunto, como um todo acabado, indiferenciado, estático, o que eqüivaleria à negação de ambos. A dicotomia e a rigidez devem ser superadas, para que se possa chegar à apreensão do movimento das relações que os vão mutuamente constituindo.

\section{Representações sociais como categoria de análise: especificidades}

Em todo este quadro teórico, qual é o espaço das representações sociais? Não estaríamos, com as colocações anteriormente feitas, confundindo ideologia e representação social ou absorvendo esta última na primeira? Ou, ainda, identificando ideologia e pensamento?

A ideologia não esgota o pensar do homem, mas está presente nas características de sua estruturação, nos referenciais do raciocínio. O que definirá a intensidade de sua presença são as complexas relações entre o objeto do pensar e o sujeito concreto que o pensa.

À representação social não está sendo associado o caráter de reprodução do real no plano subjetivo. Ela se estrutura na significação atribuída a objetos desse real, nas relações com eles estabelecidas pelo homem. "As representações sociais são princípios geradores de tomadas de posição ligadas a inserções especificas num conjunto de relações sociais e organizam os processos simbólicos que intervém nestas relações" (Doise,1986,p.84). Não está aqui em jogo um todo indiferenciado, mas objetos apreendidos, conhecidos, apropriados no processo prático, por esse homem determinado.

Nesta ótica, as representações sociais não podem ser com parti mentalizadas, desvinculadas da ideologia. Dependendo do objeto e dos grupos, bem como do tempo e do espaço, elementos provenientes da ideologia estarão pre- 
sentes, em grau maior ou menor. Isto porque a representação social é "uma forma de conhecimento socialmente elaborado e partilhado, tendo um objetivo prático e concorrendo à construção de uma realidade comum a um conjunto social"(Jodelet,1989,p.36).

A ideologia tem um caráter geral e aí está sua fluidez, sua ambigüidade e, por isso mesmo, sua força. A representação, ao contrário, se constrói e articula em torno de objetos definidos."Ela é determinada ao mesmo tempo pelo próprio sujeito (sua história, seu vivido), pelo sistema social e ideológico no qual ele se insere e pelos vínculos que o sujeito mantém com este sistema social"(Abric,1989,p.188).

Integrada num campo amplo de significações, a representação apresentará um núcleo central e polarizações secundárias que, por sua vez, poderão ser centrais para outros objetos."Este núcleo central é o elemento fundamental da representação porque é ele quem determina sua significação e organização"(Abric,1989,p.197). Quanto às polarizações secundárias, elas se constituem como tais pelas articulações que, estruturando o núcleo central, as associam em posição a ele secundária.

Essas colocações devem ser percebidas, não numa perspectiva topológica ou estática, mas em termos de um processo continuo de associações, de relações que, em diferentes niveis, vão se estabelecendo ao longo da vida, ligando significações de diversas ordens num mesmo núcleo estruturante ou campo estruturado (Jodelet, 1989, p.55), de forma a articular, para o sujeito, o sentido do objetivo representado. Para captar esse sentido é imprescindível, portanto, apreender as articulações que lhe dão substância.

Com a finalidade de concretizar - esclarecendo, tanto a dinâmica da estruturação do núcleo central, sua complexidade e amplitude, quanto as articulações que o integram num campo de significações - apresentaremos, de forma breve, dois exemplos apreendidos e analisados em pesquisas.

$\mathrm{O}$ primeiro refere-se à representação que os pequenos proprietários rurais do Semi-Árido Paraibano têm acerca dos ensinamentos que lhes são transmitidos no quadro de um Programa de Transferência de Novas 1 ecnologias ${ }^{2}$. Essa representação associa-se,de forma fundamental, ao sentido que a terra assume para esses homens. Ora, a terra, para eles, é representada como a fêmea idealizada, na relação com a qual eles se fazem e se dizem homens. Em conseqüência, a reação do homem aos ensinamentos que Ihe são transmitidos, sem considerar esta vinculação profunda, situa-se na defesa de sua identidade: ele se reconhece enquanto homem no conhecer e no lidar com a terra; pôr em questão esse saber é, para ele, questionar essa identidade e, em especial, sua masculinidade. Como polarizações secundárias aparecem a valorização da tradição, a constatação da inadequação das técnicas às suas condições

\footnotetext{
${ }^{2}$ Neste parágrafo estão resumidos o núcleo central e as principais articulações detectadas em pesquisa que atingiu 90 famílias do Semi-Árido Paraibano (Madeira, 1988). Ainda que não seja objeto do presente artigo, cumpre chamar a atenção do leitor para a construção metodológica que nos permitiu, para além de um discurso construído e defensivo sob diferentes aspectos, atingir aquele núcleo em seu dinamismo.
} 
concretas de vida, a ambigüidade entre o desejo de progredir e o medo de tudo perder, entre outras. Nota-se que as polarizações secundárias têm uma função protetora, defensiva, em relação ao núcleo central.

O outro exemplo diz respeito à representação da educação para migrantes nordestinos analfabetos (Madeira, 1983; Gomes, 1990 e Guerra, 1986). Para estes sujeitos essa representação articula-se às da vida, da morte, da fome, da família, da instabilidade no trabalho, para só citar alguns ramos de uma complexa imbricação. É, neste complexo, que o sentido da educação, enquanto transmissão de hábitos e valores, se constrói. Marcada fortemente pela acomodação e pela submissão tornadas natureza, essa educação define-os como "cabras educados", isto é, trabalhadores, respeitadores, tementes a Deus, que sabem o seu lugar. Debatendo-se na busca de um lugar para si no mundo, esses homens se representam sem espaço e sem tempo. Seu lugar é representado como o "não-lugar"; seu tempo, como acabado. No núcleo central da representação de si está a morte. O quotidiano toma-se, então, neste conjunto, a "batalha do viver", para se impedirem de pensar, pois pensar é se constatar morto. A angústia que Ihes vem pela impotência decorrente do fato de se representarem enquanto mortos, acabados, sem perspectivas, por mais que lutem ou se esforcem, leva-os a projetarem, num espaço imaginário, o desejo que, em sua quotidianidade, não tem possibilidade de expressão. O que é negado no concreto encontra, aqui, condições para se construir e se expressar. O futuro estrutura-se, então, na fantasia de projetos. Mas, note-se que, destes, eles são os sujeitos ausentes. Nem mesmo na fantasia, eles têm condições de se permitirem ser sujeitos de suas demandas. Será, apenas, através dos filhos, projeção de si, que isto se Ihes toma possível. Neste complexo, radica-se outro núcleo do sentido da educação: o que a toma como escolaridade, num projeto confuso e fantasioso, através do qual a segurança, a estabilidade e a ascensão social que são negadas a esses sujeitos seriam atingidas. Nesta representação ele é um sujeito ausente ou, como já dissemos, se faz presente pelos filhos.

O escopo da apresentação destes dois exemplos, ainda que descritos sucintamente, é patentear a complexidade que envolve o captar uma representação social. As representações são totalizações parciais e dinâmicas e, como tais, devem ser encaradas enquanto resultantes das relações possíveis com suas partes constitutivas. Considerando-as como totalizações, temos que admitir seu caráter processual, resultante da contínua interação do homem no concreto, em diferentes níveis.

É preciso levar em conta, também, que, no caso de um estudo, as escoIhas são do pesquisador, que decide ter determinado objeto como pólo: a representação de novas tecnologias ou da educação, como nos dois casos acima citados. Se fossem outros os objetos, ao aprofundarmos as análises nas direções escolhidas, outras articulações apareceriam, em maior ou menor dominância, definindo o sentido desses objetos para o segmento tomado como sujeito. No processo de estruturação do pensamento, as representações sociais são resultantes de articulações geradoras de sentido e não elementos discre- 
tos. De outra forma, estaríamos tomando as partes como o todo, o que as desvirtuaria, reduzindo-as à estagnação. A abrangência envolvida é, portanto, condição de particularização, porque é, através dela, que o sentido de um objeto se estrutura. Moscovici lembra que, se "nós as isolarmos e as separarmos umas das outras e de suas instituições, não nos restarão senão fragmentos de realidade desvitalizada, reduzida a sua expressão mais simples" (Moscovici, 1986, p.76).

Com relação às polarizações secundárias, sua situação periférica em relação ao núcleo central dá-lhes maior mobilidade potencial: podem, mais facilmente, modificar-se e adaptar-se, a partir da diversidade e da multiplicidade de informações e de experiências que o sujeito vai vivenciando. Essa mobilidade garante-lhes uma função protetora e defensiva em relação ao núcleo central que, como tal, demanda estabilidade, o que não significa, entretanto, estagnação.

Abordamos, neste momento, outro pressuposto que cumpre explicitar, é o eu do sujeito o referente básico do processo de estruturação de representações. Não um eu abstrato, mas o do homem concreto que forja sua identidade nas relações com o outro e com o mundo. Quanto mais significativo for o objeto representado para aquele que o representa, mais profundamente esse eu estará envolvido na representação e, de forma mais radical, o núcleo central desta articular-se-á com a sua identidade.

A partir deste pressuposto, o aprofundamento do estudo das representações sociais implicará a consideração da identidade do sujeito, que, ao representar um objeto, se representa nessa relação: "...uma representação é representação de alguém tanto quanto representação de alguma coisa" (Moscovici, 1969, p.11).

Como já dissemos, é evidente que existem objetos mais distanciados aqueles que, pelo nível de suas articulações, se tornam mais próximos do "núcleo identitário" do sujeito. Isto se dá mediante as relações existentes entre a significação atribuída a esse objeto pelo segmento de inserção do sujeito na totalidade social e a importância que o próprio sujeito julga ser conferida ao tal objeto pelos outros - e que ele tem como referência em sua relação com o mesmo -, além da carga afetiva que ele projeta no objeto, a partir de sua própria história pessoal. Portanto, não está aqui em jogo uma causalidade simples ou linear, mas relações complexas que, envolvendo diversos níveis e dimensões, articulam o que se convencionou chamar de representações sociais. Nesta ótica, seu estudo é um caminho para a aproximação da identidade enquanto síntese de totalidades.

Identidade não é tomada, neste texto, como sinônimo de uma individualidade que se oporia à socialidade. Ao contrário, a partir dos pressupostos colocados anteriormente, o individual contrapõem-se ao natural, ao se estruturar em relação ao social (Habermas, 1987). A identidade é aquela daquele homem em sua totalidade, naquele contexto e naquela época. Isto não nega espaço às particularidades da história pessoal de cada um, mas enfatiza que essa história, também, está nessa relação com o social. 
Ao se afirmar que as representações "...engajam a pertença social dos indivíduos com as implicações afetivas e normativas, com as interiorizações das experiências, das práticas, dos modelos, das condutas, do pensamento, socialmente inculcados ou transmitidos pela comunicação social à qual estão ligados" (Jodelet, 1989, p.37), explicita-se não só a exigência de que se considere a inserção na totalidade para sua determinação como, também, que se encare como totalidade o homem que a constrói.

As representações levam, portanto, as marcas da inserção de um segmento ou classe numa dada totalidade social. Sua estruturação se faz num processo amplo de relações que envolve diversos níveis e dimensões. Isto não se dá no isolamento de uma pretensa subjetividade independente, mas na subjetividade que se constrói em relação à objetividade, ou seja, na prática. "Não se pode eliminar da noção de representação social as referências aos mútiplos processos individuais, interindividuais, intergrupais e ideológicos que, freqüentemente, entram em ressonância uns com os outros e cuja dinâmica de conjunto chega a estas realidades vivas que são, em última instância, as representações sociais" (Doise, 1986, p.83). Assim, são gerados, ratificados e ampliados valores, normas, símbolos e conceitos, aspectos que comportam, evidentemente, caráter ideológico; assim, as imagens adquirem sua força, as aspirações e expectativas se sedimentam; assim, o externo é internalizado e a síntese gerada, por sua vez, externaliza-se; assim, o homem se expressa na comunicação e na conduta, e as respostas que encontra a essa expressão vão transformando, sutilmente, a própria representação.

\section{Conclusões}

Todo esse processo não pode ser isolado da ideologia, nem a ela ser identificado. Não pode ser isolado porque as idéias dominantes em uma sociedade deixam seus traços em todo o homem que a integra Não pode ser identificado porque isto seria negar a concretitude da negatividade potencial presente em cada homem, reduzindo-o, então, a mero reprodutor do já feito.

As representações sociais, estruturando-se como uma forma de conhecimento social, um saber prático, levam as marcas das contradições e conflitos desse mesmo social que elas articulam nas comunicações e nas condutas (Jodelet, 1984, p.360).

Tenha-se presente, também, o caráter geral e difuso da ideologia e a característica de particularização através da prática, própria da representação.

É no crivo dessa prática que a negatividade tem seu espaço potencial. Será por ela que o estabelecido e o instituído, ao se encarnarem na temporalidade e na espacialidade, se tornam provisórios, logo, potencialmente transformáveis.

Neste sentido, estruturando-se na prática, a representação social fala do que é, ao mesmo tempo que diz do que pode ser. Como tem suas fontes na experiência das idéias que circulam, ela tende a afirmar o que é; como, entre- 
tanto, essas idéias lhe chegam através dessa mesma experiência, as contradições com o estatuído também estão presentes. Disto decorre a dualidade e a ambigüidade que assumem certas representações para determinados grupos. Afetivo, emocional, latente, instintivo são outras tantas dimensões que estão presentes, articulando núcleos cada vez mais complexos de sentido. Estes integram e relacionam, num mesmo pólo significante, momentos e experiências aparentemente diversos.

Além disto, como a representação não se inscreve no vazio, ela "encontra sempre um já pensado, latente ou manifesto" (Jodelet, 1984, p.375); o encontro da novidade com este conjunto já estabelecido gera, também, certo confronto característico de um processo complexo de relações.

Destas colocações decorre que o sentido de uma representação social não pode ser captado no dado, no imediato, no manifesto, nem na existência de questões, temas ou reflexões comuns a grupos de sujeitos. A representação não será apreendida isolada do conjunto. Seu sentido profundo vem das articulações que mantém com outros pólos significantes a ela ligados. Não se esgota no manifesto, mas está nas imbricações deste com o que lhe é latente. Não se restringe ao falar, mas tem que ser buscado nas relações deste com o dizer. 0 dizer muitas vezes irrompe ou faz sentir sua presença na sutileza dos silêncios, dos risos, das hesitações ou de outros tantos mecanismos, os quais o homem vai estruturando ao longo da vida, como formas de se proteger do afloramento daquilo que não tem espaço, nem mesmo em si próprio, para ser dito.

A consideração dos pressupostos que embasam esta abordagem da representação social e das dimensões e níveis nela implicados parece-nos importante pois, a partir dela, se podem abrir outras vias para a análise e a compreensão do processo histórico, com vistas a uma participação efetiva, inclusive através do espaço da educação.

A educação é construída nas relações concretas da totalidde social. Traz suas marcas e contradições. Não é um ato isolado, nem decorre da boa vontade de indivíduos ou da idealização de dirigentes. Entre o discurso destes e a prática quotidiana está a distância entre os efetivos interesses em jogo, interesses que extrapolam a educação e que têm suas raízes nas relações sociais mais amplas, determinando-a.

Leve-se em conta, também, que a significação da educação, longe de ser uniforme, é diversa, pois diversas são as formas de inserção na totalidade social. Como já analisamos, uma representação não se estrutura no abstrato, nem isoladamente. Não existe independente do viver e do sobreviver. A grande ilusão está em pensar e agir como se uma única representação de educação, de escola e de escolaridade fosse possível, e o que se apresentasse como diferente, um mal a ser, de alguma forma, extirpado.

Mas, olhando a realidade das escolas que existem à revelia do povo que as deveria freqüentar, e que as rejeita porque se apercebe rejeitado por elas; de homens e mulheres que cronologicamente seriam jovens, mas que se representam, e são velhos, desgastados precocemente pelo esforço do viver, de

R. bras. Est. pedag. Brasília,-72(171):129-144, maio/ago. 1991 
homens e mulheres que encontram na acomodação ou na revolta surda e muda seu espaço de sobrevivência, não é de se impor questionamentos profunoos acerca de nossos caminhos e do espaço da educação? Será que não continuamos a construir educação para este povo (ou apesar dele), e em seu nome, no desconhecimento de seu concreto pela omissão e sua voz? Conhecemos os referentes básicos do pensar e do agir daqueles que são objeto de propostas, programas e ações? Ou continuamos, mesmo quando o discurso proclamado vai noutra direção, a pensar e a fazer educação como uma forma à qual o individuo deveria se adaptar para se tornar razoavelmente aceitável? Conhecemos o homem concreto, que é feito objeto de propostas educativas, ou agimos e reagimos a partir de nossas próprias representações acerca dele, de seu espaço e de seu futuro?

São questões que se impõem. Podem até ser tidas como ingênuas, simplistas, idealistas ou outros tantos rótulos que justificam o alijamento do que foge ao estereotipado, ao modismo, ao lugar comum, no faz-de-conta que nos marca histórica e concretamente, e do qual todos somos vitimas e construtores. As raízes destas questões, no entanto, continuam a gritar mais alto na voz calada desses homens, mulheres e crianças.

A captação e a análise das representações sociais da educação, da escola e do processo educativo, por exemplo, podem se constituir num caminho para a captação dessa voz, para a compreensão desses homens. Não se trata de cair numa postura ingênua, que negaria a complexidade envolvida, tomando a fala do homem como dado acabado e imediato, parâmetro exclusivo e excludente a partir do qual o processo educativo deveria se definir. A representação social espelha a dialética entre o que aí está e o que já está em gestação. Ao se perder de vista esta complexidade, perde-se a possibilidade de apreensão do fenômeno em sua dinâmica. A consideração do homem como totalidade continuamente em estruturação, em suas relações com a totalidade social mais ampla, exige que se tomem suas expressões nesse bojo. Exige que se busquem caminhos de aproximação ao fenômeno que o apreendam nesse complexo. Do contrário, estaríamos, mais uma vez, desrealizando o homem, pela negação do espaço histórico que é seu, e manipulando-o em nome, talvez, do respeito ao que seria "sua realidade", superfície sem substrato, momento sem história, continente sem conteúdo. É na comunicação livre e na conduta tomadas como totalidades que uma representação social pode ser apreendida em sua riqueza, em seu potencial transformador. É aí que se pode buscar o sentido da educação para diferentes segmentos de uma totalidade social. É a partir daí que propostas educativas pertinentes poderiam ser articuladas. Caminhar-se-ia, então, para a superação do caráter, que às vezes assumem, de transmissão de um acervo vazio, de treinamentos aparentemente sem referentes ou de manipulação místificadora. O processo educativo partiria de pólos densamente significantes para os grupos, de forma que, potencializados, esses pólos encontrassem condições de organização e de expressão, no concreto do indivíduo social. 
ABRIC, J. C. L'étude experimentale des représentations Sociales. In: JODELET, D. (Ed.). Les représentations Sociales. Paris: PUF, 1989.

ASTOLFI, J. P., GIORDAN, A. Quelle éducation scientifique pour quelle société? Paris: PUF, 1973.

BELISLE, C, SCHIELE, B. (Eds.). Les Savoirs dans les pratiques quotidiennes. Lyon: CNRS, 1984.

DOISE, W. Les représentations Sociales: définition d'un concept. In: DOISE, W., PALMONARI, A. (Eds.). Létude des représentations Sociales. Paris: Delachaux \& Niestlé, 1986.

DURKHEIM, É. Les formes élémentaires de la vie religieuse. Paris: PUF, 1968.

GOMES, Gerusa de Mendonça. A experiência do vazio: significação da educação para migrantes de retorno. Recife: Massangana, 1990.

GUERRA, Yaponira B. O espaço dos sem espaço: estudo de caso de migrantes de classes subalternas em Recife. João Pessoa, 1986. Dissertação (Mestrado em Educação) - Universidade Federal da Paraíba, 1986.

HABERMAS, J. Para a reconstrução do materialismo histórica São Paulo: Brasiliense, 1990.

----- Théorie de l'agir communicationnel. Paris: Fayard, 1987. t1 e 2.

JACOBI, D., SCHIELE, B. Vulgaríser la science: le procés de l'ignorance. Champ Vallon: Diffusion; Paris: PUF, 1988.

JODELET, D. Représentations sociale: phénomènes, concept et théorie. In: MOSCOVICl, S. Psychologie sociale. Paris: PUF, 1984.

. Représentations Sociales: un domaine en expansion. In (Ed.). Les re présentations Sociales. Paris: PUF, 1989.

KAÊS, R. Psychanalyse et representation sociale. In: JODELET, D. (Ed.). Les représentations Sociales. Paris: PUF, 1989.

LOWY, M. Paysages de la vérité. Paris: Anthropos, 1985.

LUKÁCS, G. Histoire et conscience de classe. Paris: Ed. Minuit, 1960

MADEIRA, Margot. Aspirações à educação: estudo do caso de migrantes nordestinos no Rio de Janeiro. Paris, 1983. Tese (Doutorado) - Université de Paris, 1983.

. Avaliação psicossocial de processos de difusão controlada de novas tecnolo gias: representações de proprietários, seus familiares e trabalhadores. [S.I.:s.n.J, 1988. Pesquisa financiada pelo CNPq-BIRD.

MOSCOVICI, S. Des représentations collectives aux représentations Sociales. In: JODELET, D.(Ed.). Les représentations Sociales. Paris: PUF, 1989.

. L'ére des représentations Sociales. In: DOISE, W., PALMONARI, A. (Eds.).

L'étude des représentations Sociales. Paris: Delachaux \& Niestlé, 1986.

-----. Préface. In: HERZLICH, C. Santé et maladie analyse d'une representation sociale. Paris: Mouton, 1969. 
----- . La Psychanalyse: son image et son publique. Paris: PUF, 1961.

MOSCOVICI, S., HEWSTONE, M. De la science au sens commun. In: MOSCOVICI,

S. Psychologie sociale. Paris: PUF, 1984. PROTÉE. La divulgation du savoir.

Chicoutimi: Département des Arts et Lettres de

I'UQAC, v.I 6, n.A3, aut. 1988.

Recebido em 1 de julho de 1991

Margot Campos Madeira, doutora em Psicologia pela Universidade Paris X, é consultora da Revista Ciência \& Trópico.

In this article social representation is seen as the particularization in give item, of an ampler process of man's aprehension of reality as subject-agent in specific time and space. The basic tools for the structuring of the theoretical proposition are: the category ofwholeness, the principie of contradiction and the rules of movimcnt. This paper presents some consequences ofapplying such approach to some existing educational questions.

La representation sociale est envisagée dans cet article comme une particularisation, dans un objet, du procès le plus large dappréhension et d'appropriation du réel par Vhomme, tandis que sujet-agent place dans un temps et dans un space. La cathégorie de totalité, le príncipe de contradiction et là loi du mouvement sont les outils de base pour Ia construction de là proposition théorique. On presenté quelques implications de l'application de cette approche aux questions concrètes d'éducation.

La representación social se aborda en este artículo como là particularización, en un objeto, del proceso más amplio de aprehension y dela apropiación de Io real por el homhre, en cuanto sujeto-agente situado en un tiempo y un espacio. La categoria de totalidad, el principio de contradicción y là del movimiento son los instrumentos básicos para Ia construcción de là propuesta teórica. Se levantan algunas implicaciones relativas a là aplicación de este abordaje a Cuestiones concretas de educación. 